\title{
Effect of p-Fluorophenylalanine on the Synthesis of Vaccinia Virus ${ }^{1}$
}

\author{
PHILIP C. TOH ${ }^{2}$ AND FRANCIS E. PAYNE \\ Department of Epidemiology and Virus Laboratory, School of Public Health, University of \\ Michigan, Ann Arbor, Michigan \\ Accepted January $\gamma, 1965$
}

\begin{abstract}
The effect of the amino acid analog FPA on vaccinia virus replication in HeLa cells was investigated. By varying the dose of FPA or the time after infection at which the analog was added to cultures, it was possible to inhibit differentially the synthesis of viral components in vaceinia-infected cells. When sufficient FPA was added to cultures at the time of infection, the synthesis of viral DNA, NP antigen, infectious virus, and HA was inhibited. The inhibition of synthesis of LS antigen under all conditions studied was only partial. FPA added to cultures at 6 or more hours post-infection did not inhibit production of viral antigens or infectious virus.

The inhibition was reversed by PA added with the FPA, but PA added at later times was progressively less effective in restoring the ability of inhibited infected eultures to produce virus.

The proportion of nuclei incorporating thymidine- $\mathrm{H}^{3}$ was decreased in cultures infected with vaccinia virus. This decrease was not seen in cultures receiving FPA at the time of infection.
\end{abstract}

\section{INTRODUCTION}

In a previous study cytochemical and immunofluorescence techniques revealed that detectable amounts of viral nucleic acid and various viral antigens appeared in an orderly sequence in cells infected with vaccinia virus (Loh and Riggs, 1961). Viral $\mathrm{DNA}^{3}$ and the Lis antigen (Shedlovsky and Smadel, 1942) were the first to be detected, followed by the NP antigen (Smadel et al., 1942), infectious virus, and lastly, vaccinial

\footnotetext{
Aided by a grant from The National Foundation.

${ }^{2}$ Present address: Department of Microbiology, University of Hawaii, Honolulu, Hawaii.

${ }^{3}$ Abbreviations: BME, basal medium Eagle's; BSS, Hanks' balanced salt solution; CAV, cellassociated virus; DNA, deoxyribonueleic acid; EM, experimental medium; FPA, $p$-fluorophenylalanine; HA, hemagglutinin; HAU, hemagglutination unit; LS antigen, heat-labile-heat-stable antigen; NP antigen, nucleoprotein antigen; PA, phenylalanine; PFU, pock.forming unit; RNA, ribonucleic acid.
}

HA (Burnet and Stone, 1946). Although suggestive, these temporal relationships did not establish that the synthesis of any one of the above products of the infected cell was prerequisite to the synthesis of another. Thus, in the hope of clarifying possible relationships among segments of viral synthesis, studies on the synthesis of viral constituents in the presence of inhibitors of viral replication were undertaken.

It was first reported by Ackermann et $a$. (1954) that FPA markedly inhibited replication of poliovirus but that this amino acid analog did not interfere with the development of cytopathology in HeLa cells infected with poliovirus. Subsequently, several authors have found that FPA differentially interferes with the synthesis of components of animal viruses containing RNA (Zimmermann and Schäfer, 1960; Wecker and Schonne, 1961; Brown et al., 1961; Scholtissek and Rott, 1961; Levintow et al., 1962; Wecker et al., 1962). After the present study was completed, three investigators 
reported that FPA interfered with protein synthesis in cells infected with poxviruses. Joklik (1962) described the inhibition by FPA of the "uncoating" of rabbitpox virus, and Salzman et al. (1963) reported that FPA inhibited a reaction which occurs late in the formation of vaccinia virus. Also, Kit et al. (1963) have used FPA to interfere with the increase in thymidine kinase activity observed in cells infected with vaccinia virus.

The present investigation reports on the effects of FPA on the synthesis of infectious vaccinia virus, viral nucleic acid, NP and LS antigen, and vaccinial hemagglutinin.

\section{MATERIALS AND METHODS}

Cell cultures. HeIa cells originally obtained from Difco Laboratories were routinely cultivated in BME (Eagle et al., 1957) conlaining $10 \%$ equine serum. Stationary tube cultures for experiments were initiated with $3.5 \times 10^{4}$ cells in $1 \mathrm{ml}$ of medium. For cytologic studies coverlips were placed in Leighton or screw cap tubes prior to the addition of cells. All cultures were incubated at $37^{\circ} \mathrm{C}$ and used 4 days after initiation.

Virus. The virus used in all experiments was obtained originally from calf lymph vaccine prepared by the Michigan Department of Health. The virus stock was the fourth passage of this virus in HeLa cells and contained approximately $3.0 \times 10^{8}$ PFU per milliliter.

Chemicals. DL-p-Fluorophenylalanine and u-phenylalanine were obtained from Nutritional Biochemical Corporation. Methyllabeled thymidine- $\mathrm{H}^{3}$ with a specific activity of 5.21 curies/mmole was obtained from New England Nuclear Corporation.

Assays:

Infectious virus was assayed on chorioallantoic membranes of 12-day-old embryonated chick eggs according to the method of Beveridge and Burnet (1946). Titers were expressed as PFU per milliliter.

Vaccinial $H A$ was quantitated using lipidsensitive chicken erythrocytes as described by Kempe (1956). One hemagglutination unit (HAU) was the minimum amount of HA required to produce complete agglutination of the erythrocytes.
$L S$ and NP antigens were detected by immunofluorescent staining. The specific fluorescein-conjugated immune gamma globulins against LS and NP antigens were prepared and tested previously (Loh and Riggs, 1961). These globulins did not stain uninfected HeLa cells and were specific when tested by the quantitative precipitin method of Cohn (1952).

Cells for immunofluorescent staining were fixed at or before 12 hours p.i. because at later times rounding of infected cells made difficult the delineation of viral antigen within cells. Cells on coverslips were washed three times with $1 \mathrm{ml}$ of BSS, fixed in cold acetone, and stained according to the technique of Coons and Kaplan (1950). Stained cells were examined under a Zeiss microscope (GF 425) equipped with an Osram lamp (HBO 200), exciter filter (BG12 or UG2), and ocular barrier filters (OG4 and GG4). The proportion of cells stained with the fluorescein-labeled globulin was determined by counting five areas of 200 cells per area on each of duplicate coverslips. Cells were scored as containing antigen if they showed any yellow-green fluorescence.

The minimum amount of either NP or LS antigen detected by staining with fluorescent antibody was unknown; however, it was considered to be quite small since Cairns (1960), using fluorescent antibody presumably prepared against whole vaccinia virus, noted that single virus particles adsorbed enough antibody to appear as minute points of fluorescence. Although the absence of staining by specific antibody might have resulted from either lack of synthesis of antigen or production of antigen so modified that it did not react with antibody, these alternatives were considered operationally equivalent since severely modified viral protein would probably be nonfunctional. With these reservations in mind, a cell that did not stain with specific fluorescent antibody was considered a cell that had not synthesized antigen.

The amount of viral antigen synthesized in cells of cultures treated with inhibitor was estimated by comparing the size and intensity of staining of their cytoplasmic inclusions with those seen in untreated cells at 
various times after infection. The extent to which the quantity of viral antigen in a cell that stained might vary without perceptibly altering these parameters has not been established.

Incorporation of tritiated thymidine. Where noted, coverslip cultures were exposed to thymidine $-\mathrm{H}^{3}(0.5 \mu \mathrm{c} / \mathrm{ml}$ of medium) for the indicated period. After the cells on coverslips had been examined by the fluorescent antibody method, they were washed with cold $2 \%$ perchloric acid, fixed in Carnoy's solution, and processed according to the procedure of Messier and Leblond (1957). Coverslips coated with emulsion (Kodak Nuclear Track Type NTB3) were stored at $4^{\circ}$ for $1-2$ weeks. The emulsion was developed and the cells were stained with Giemsa's stain. When one or more foci of six or more closely associated silver grains appeared over the cytoplasm of a cell, the cell was considered to have incorporated thymidine- $\mathrm{H}^{3}$ into viral DNA. Nuclei over which six or more grains were seen were considered to have incorporated thymidine- $\mathrm{H}^{3}$ into nuclear DNA. The proportion of cells incorporating thymidine- $\mathrm{H}^{3}$ was determined by counting five areas of 200 cells per area on each of duplicate coverslips.

Fluorochrome staining. Acridine orange was used according to the technique described by Armstrong and Niven (1957).

Experimental procedure. Cell cultures were washed with three $1-\mathrm{ml}$ portions of BSS and changed to $1 \mathrm{ml}$ of the experimental medium (EM) consisting of BME and $2 \%$ equine serum. Cultures were infected by incubation for 2 hours at $37^{\circ}$ with $1 \mathrm{ml}$ of EM containing virus at a multiplicity of exposure of approximately $20 \mathrm{PFU}$ per cell. At the end of this period unadsorbed virus was removed by washing the cultures with three $1-\mathrm{ml}$ portions of BSS. One milliliter of EM was then added, and the cultures incubated further at $37^{\circ}$. As judged by the proportion of cells containing viral antigen, this procedure resulted in the infection of more than $85 \%$ of the cells. The time at which virus was added to the cultures was considered 0 time.

At times indicated in the individual experiments, various concentrations of FPA were added to the EM which containcd PA at a concentration of $16 \mu \mathrm{g} / \mathrm{ml}$. When

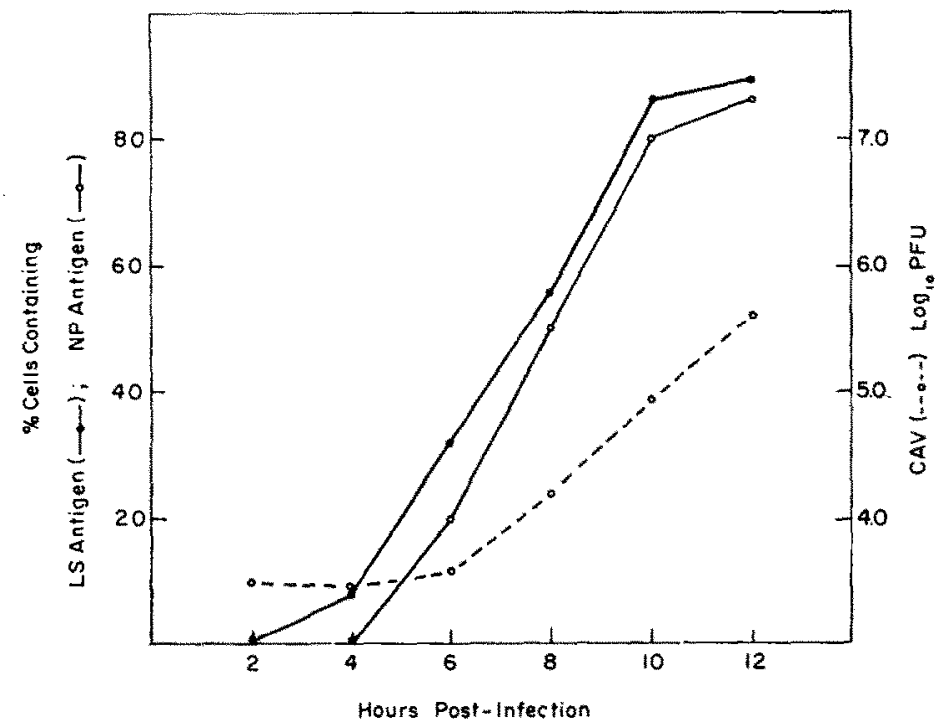

Fra. 1. Development of LS antigen, NP antigen, and cell-associated virus (CAV) in HeLa cells infected with vaccinia virus. Cell cultures were incubated with virus (exposure multiplicity $=20$ ) for 2 hours at $37^{\circ} \mathrm{C}$, washed, and further incubated at $37^{\circ}$. Coverslip preparations were fixed at various times p.i. and stained with fuorescent antibody for determination of the proportion of cells containing viral antigen. Replicate cultures were washed and frozen at the indicated times for subsequent measurement of CAV as described in Materials and Methods. 
cultures were treated with FPA during the adsorption period, the BSS used to wash the cultures at the end of this period and the EM subsequently added contained the indicated concentration of FPA.

Control cultures were handled in the same manner as those described above except that virus, inhibitor, or both, as indicated were not added to the medium.

At intervals following infection, sample cultures were harvested for measurement of viral replication. Yields of infectious virus and $\mathrm{HA}$ were determined on samples from cultures in which the cells were disrupted in the medium by four cycles of freezing and thawing followed by sonic oscillation (10 kc for 5 minutes). For measurement of CAV the cellular monolayers were washed with three 1-ml portions of BSS and disrupted as above in $1 \mathrm{ml}$ of fresh EM. Cultures containing coverslips were washed with BSS, and the cells were fixed in acetone for determination of the proportion of cells containing viral antigen or thymidine- $\mathrm{H}^{3}$.

\section{RESULTS}

\section{Development of Vaccinal Antigens and Infectious Virus}

In cultures inoculated with $20 \mathrm{PFU}$ of virus per cell and stained at intervals with fluorescent antibody, LS antigen was detected in a small proportion of the cells between 2 and 4 hours p.i. NP antigen was not demonstrable until between 4 and 6 hours p.i. Curves indicating the rate of increase in the proportions of cells containing these antigens (Fig. 1) were essentially parallel, and that for LS antigen preceded that for NP. The CAV in these cultures first increased at about 6 hours p.i. and reached a plateau at about 24 hours p.i. Vaccinial hemagglutinin was first detected at about 10 hours p.i. and was routincly assayed at 24 hours p.i.

The proportion of cells containing NP antigen at 12 hours p.i. was related to exposure multiplicity as shown in Fig. 2.

\section{Effect of FPA on the Formation of Vaccinial Antigens and Infectious Virus}

FPA in varying concentrations was added with the virus to a series of replicate HeLa

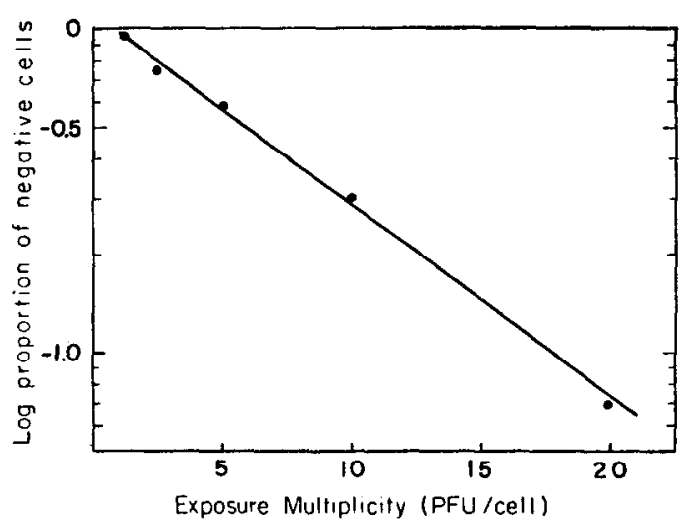

FIG. 2. Relationship between exposure multiplicity and proportion of HeLa cells containing NP antigen at 12 hours after infection with vaccinia virus. Cell cultures were incubated with various multiplicities of virus for 2 hours at $37^{\circ} \mathrm{C}$, washed and incubated further at $37^{\circ}$. Coverslip preparations were fixed at 12 hours p.i. and stained with fluorescent antibody for determining the proportion of cells containing NP antigen.

cell cultures. At 10 hours p.i. coverslip preparations were fixed for staining with fluorescent antibody and enumeration of cells containing viral antigen. Yields of infectious virus and $\mathrm{HA}$ were determined on samples from cultures incubated until 24 hours p.i.

As seen in Fig. 3, cultures treated with FPA at a concentration of $200 \mu \mathrm{g} / \mathrm{ml}$ yielded only $10 \%$ as much infectious virus as untreated infected controls. With concentrations of $300 \mu \mathrm{g} / \mathrm{ml}$ and above, the amount of virus per culture at 24 hours p.i. was the same as that present after washing the culture at the end of the adsorption period and less than $0.1 \%$ of that produced by cultures not treated with FPA.

With $200 \mu \mathrm{g} / \mathrm{ml}$ of FPA, the yield of HA, unlike that of infectious virus was not detectably decreased. However, with 300 $\mu \mathrm{g} / \mathrm{ml}$ and above, the yield of HA like that of virus was markedly decreased.

At concentrations of FPA of $200 \mu \mathrm{g} / \mathrm{ml}$ or greater, the proportion of cells containing NP or LS antigen was decreased, but those cells that did stain for these antigens showed fluorescence comparable in intensity and intracellular distribution to that seen in the untreated infected control cells. This ob- 

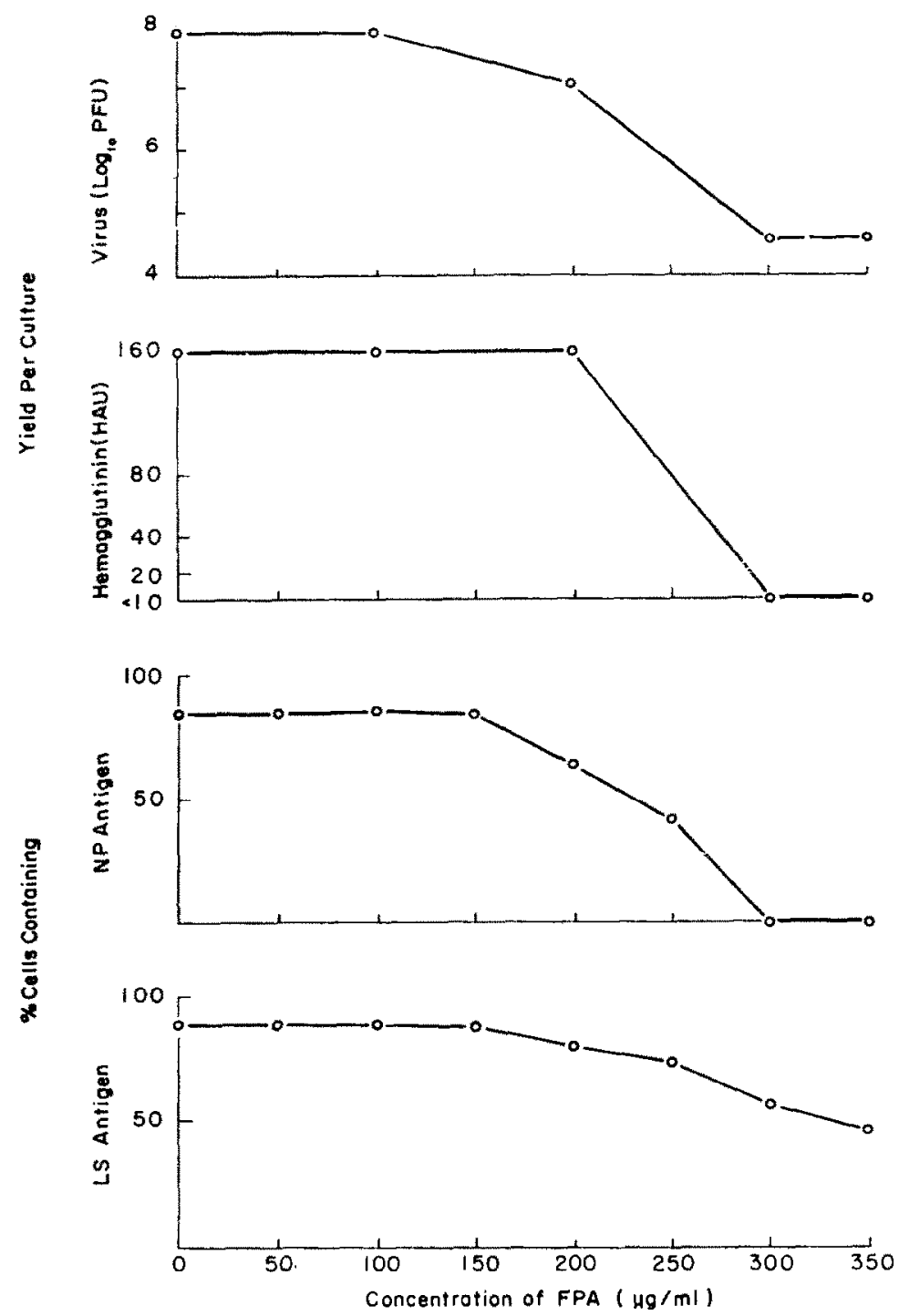

Fig. 3. The effect of $p$-fluorophenylalanine on the formation of vaceinia virus, vaceinial hemagglutinin, NP antigen, and LS antigen in HeLa cells. Cell eultures were incubated with virus and the indicated concentration of FPA for 2 hours at $37^{\circ} \mathrm{C}$, washed, and further incubated in EM containing FPA at that concentration present during the adsorption period. Coverslip preparations were fixed at 10 hours p.i. and stained with fluorescent antibody for determination of the proportion of cells containing viral antigen. Replicate cultures were frozen at 24 hours p.i. for subsequent measurement of the yields of infectious virus and hemagglutinin.

servation suggested that the production of either NP or LS antigen, once initiated, had proceeded in these cells in the presence of FPA. Thus, since at 300 and $350 \mu \mathrm{g} / \mathrm{ml}$ of FPA none of the infected cells contained detectable NP antigen whereas about $50 \%$ of the cells were stained heavily with anti- body against LS antigen, it seemed that the initiation of synthesis of NP antigen was more sensitive to FPA than was that of LS antigen.

Because $300 \mu \mathrm{y} / \mathrm{ml}$ of FPA produced apparently complete inhibition of synthesis of infectious virus, NP antigen, and $H A$, 


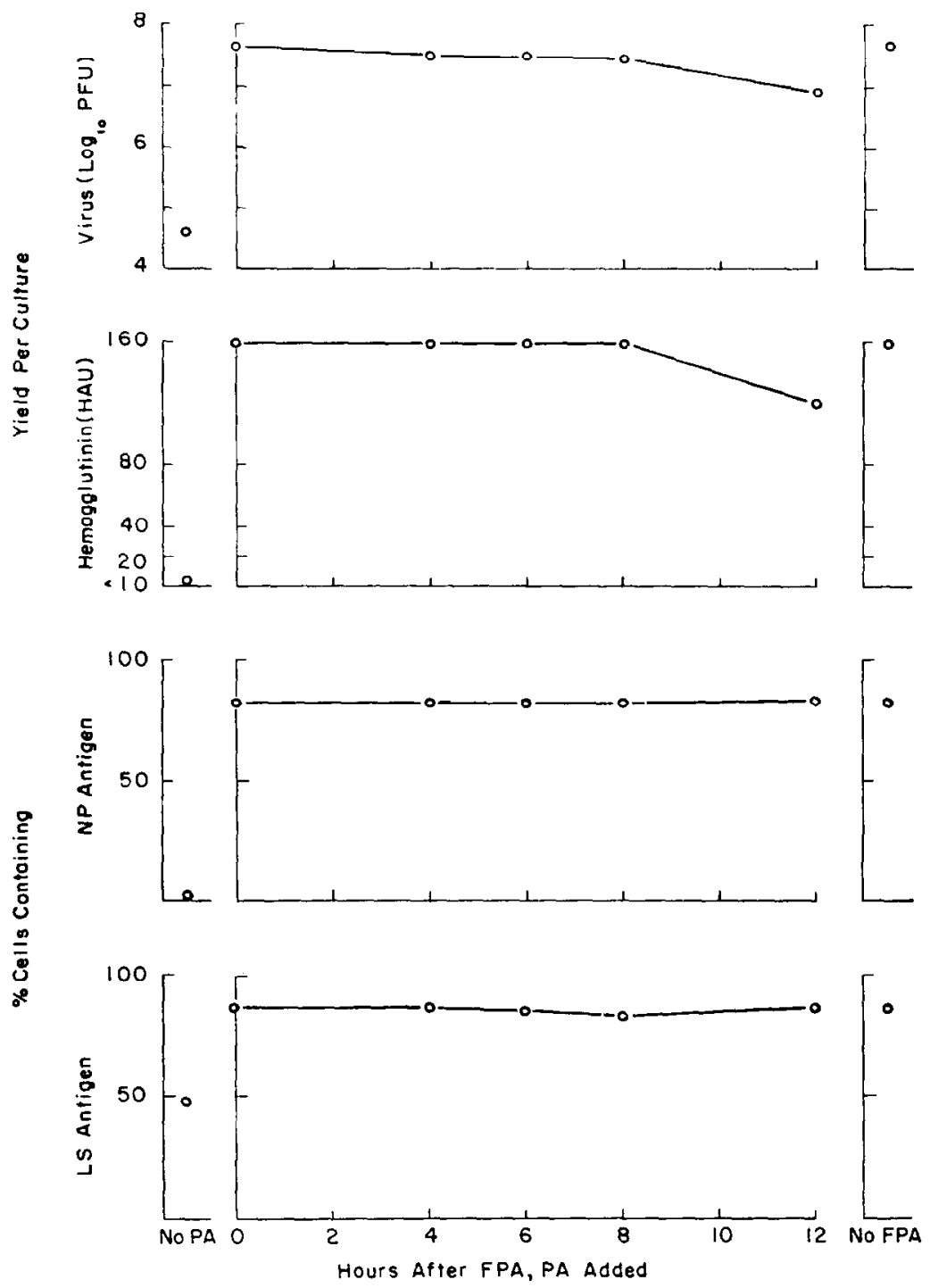

FIG. 4. Effect of phenylalanine added at various intervals after the simultaneous addition of virus and $p$-fluorophenylalanine to HeLa cell cultures on the production of vaccinia virus, vaceinial hemagglutinin, NP antigen, and LS antigen. FPA $(300 \mu \mathrm{g} / \mathrm{ml})$ was added along with virus to replicate cultures. Cultures were incubated for 2 hours at $37^{\circ} \mathrm{C}$, washed and further incubated at $37^{\circ}$ in $\mathrm{EM}$ containing FPA. L-Phenylalanine $(600 \mu \mathrm{g} / \mathrm{ml})$ was added at various times p.i. as indicated. Control cultures were treated in the same manner except that one set received no PA and the other no FPA. For determination of the proportion of cells containing antigen, coverslips were fixed at 10 hours after the addition of PA and, in the case of the controls, at 10 hours p.i. Yields of infectious virus and HA were determined in cultures frozen at 24 hours after the addition of PA and, in the case of controls, at 24 hours p.i.

this dose was chosen for subsequent experiments.

\section{Reversal of FPA-Inhibition by the Addition of} Phenylalanine

FPA was added with virus to a series of replicate cell cultures, and a greater than equimolar amount of L-phenylalanine was added at varying intervals after infection as indicated in Fig. 4. Control cultures received virus and FPA or virus alone. For enumeration of cells containing antigen, coverslips were fixed at 10 hours after the addition of 
PA or at 10 hours p.i. in the case of the control cultures. Yields of infectious virus and HA were determined in cultures ineubated for 24 hours after the addition of PA or for 24 hours p.i. in the case of the controls.

The results (Fig. 4) indicated that the inhibition of synthesis of infectious virus, HA, NP, and LS antigen was reversed by the addition of PA to the cultures. However, FPA-inhibited cultures to which PA was added as early as 4 hours p.i. yielded $15 \%$ less virus than those cultures reversed with PA at 0 hours p.i. or those not treated with FPA. PA added at times after 4 hours p.i. was progressively less effective in restoring the ability of FPA-treated cultures to produce infectious virus. When PA was added at 12 hours p.i. only $20 \%$ of the expected yield of virus resulted and there was also a detectable decrease in production of $\mathrm{HA}$. In related experiments, it was found that uninfected cultures incubated with FPA $(300 \mu \mathrm{g} / \mathrm{ml})$ for as long as 12 hours underwent no discernible morphologic alterations and, when treated with PA, supported vaccinia virus replication as well as cultures not treated with the analog. This suggested that the observed decrease in yields of virus and HA from inhibited cultures treated with PA was not attributable to an irreversible effect of FPA on the cells per se. Rather, it suggested an irreversible effect of FPA on viral replication or possibly an effect of the viral inoculum, not inhibited by FPA, that damaged the cells.

As seen in Fig. 4, cultures treated with FPA and receiving $\mathrm{PA}$ as late as 12 hours p.i. did contain as many cells producing NP and LS antigen as infected cultures not treated with FPA. Thus, inhibition of processes leading to the initiation of synthesis of these antigens in a cell was reversed by PA. That the proportion of cells containing viral antigen was the same as in the untreated infected controls also indicated that FPA had not interfered with viral adsorption since, as seen in Fig. 2, decreases in exposure multiplicity below 20 progressively decreased the proportion of cells containing antigen. Although the intensity of fluorescent staining of cells in cultures reversed by PA at 12 hours p.i. was not perceptibly different from that seen in the untreated infected cultures, it was possible that the quantity or quality of antigen in the reversed cultures was suboptimal and accounted for the decreased yields of virus in these cultures.

The reversal of FPA-inhibition by added PA was further examined by determining the rate of production of infectious virus and the rate of increase in the proportion of cells producing antigen in PA-reversed cultures. One set of cultures was inoculated with virus and a replicate set received virus and FPA. At 6 hours p.i. the inhibited cultures received PA $(600 \mu \mathrm{g} / \mathrm{ml})$. At 2 -hour intervals p.i. coverslips were fixed for enumeration of cells containing antigen and cultures were washed and frozen for subsequent determination of $\mathrm{CAV}$.

In Fig. 5, it is seen that cells containing NP antigen were not detected in the control cultures until 4 hours p.i. and CAV did not increase until 6 hours p.i. Cells in the FPAtreated cultures contained detectable NP antigen at 2 hours after the addition of $\mathrm{P} \Lambda$, and CAV was observed to increase 4 hours after PA. The shortened lag period in the reversed cultures indicted that the inhibited system had reached an early stage of viral development and had not progressed. Since the rate of production of virus and the rate of increase in the proportion of cells with NP antigen in the PA-reversed cultures were essentially the same as those in control cultures, there had been no progressive accumulation of viral precursor or if such had occurred, the precursor was either nonfunctional or its production was not rate limiting in either the synthesis of virus or the development of the cells ability to synthesize NP antigen.

\section{Effect of FPA Added at Different Times in the Infectious Sequence}

In an attempt to relate FPA-sensitive reactions to the stages of viral replication and the synthesis of products of the infected cell, the analog was added to cultures at various times after infection. Also, since a lag between the time of addition of FPA and the time at which it became effective 


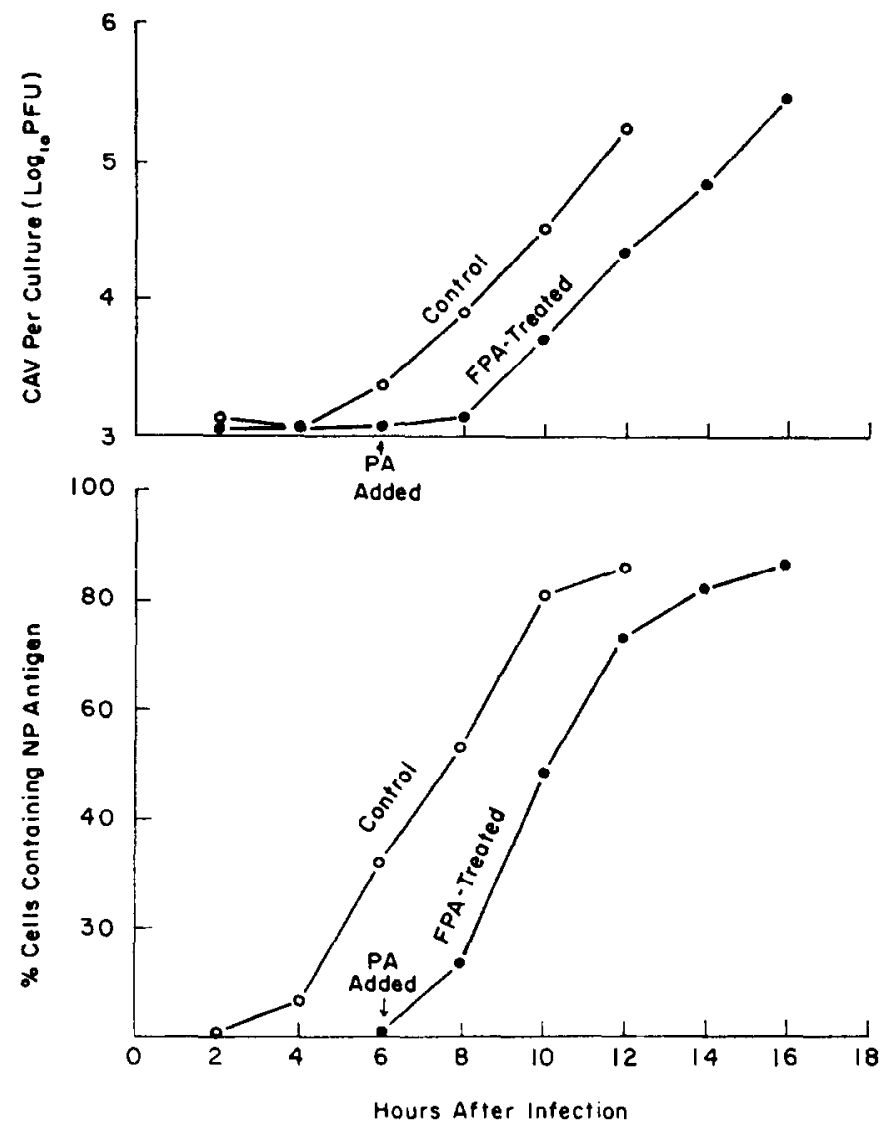

FIG. 5. Effect of phenylalanine added at 6 hours after the simultaneous addition of $p$-fluorophenylalanine and virus to HeLa cells on the production of vaccinia virus and NP antigen. Control cultures were inoculated with virus and a replicate set received virus and FPA $(300 \mu \mathrm{g} / \mathrm{ml})$. The cultures were incubated for 2 hours at $37^{\circ} \mathrm{C}$, washed, and incubated further in EM. The FPA-treated cultures received EM containing FPA following the wash. At 6 hours p.i., PA was added to the FPA-treated cultures to give a concentration of $600 \mu \mathrm{g} / \mathrm{ml}$. At 2-hour intervals p.i., coverslips were fixed for enumeration of cells containing NP antigen and cultures were washed and frozen for determination of cell-associated virus (CAV).

might have accounted for the production of LS antigen in cultures receiving analog at 0 time, FPA was added to some cultures 12 hours before infection. The proportion of cells containing NP and LS antigen was determined at 10 hours p.i., and yields of infectious virus and HA wcre detcrmined on samples taken at 24 hours p.i.

As shown in Fig. 6, the synthesis of infectious virus, HA, and NP antigen was completely inhibited when FPA was added at 0 or -12 hours p.i. When the analog was added at 1 hour p.i., there was subsequent synthesis of NP antigen by some cells. Inhibitor added at 2 or 3 hours p.i. allowed syn- thesis of detectable amounts of infectious virus and HA. In infected control cultures the first detectable production of NP antigen, virus and HA had occurred at about 4,6 , and 10 hours p.i., respectively. When FPA was added at 6 hours p.i. or later there was no apparent inhibition of synthesis of virus or $\mathrm{HA}$ and the proportion of cells containing NP or LS antigen was the same as in uninhibited cultures.

If FPA became effective shortly after it was added to the cultures, the above observations would indicate that FPA-sensitive reactions concerned with the synthesis of $\mathrm{NP}$ antigen, infectious virus, and $\mathrm{HA}$ oc- 

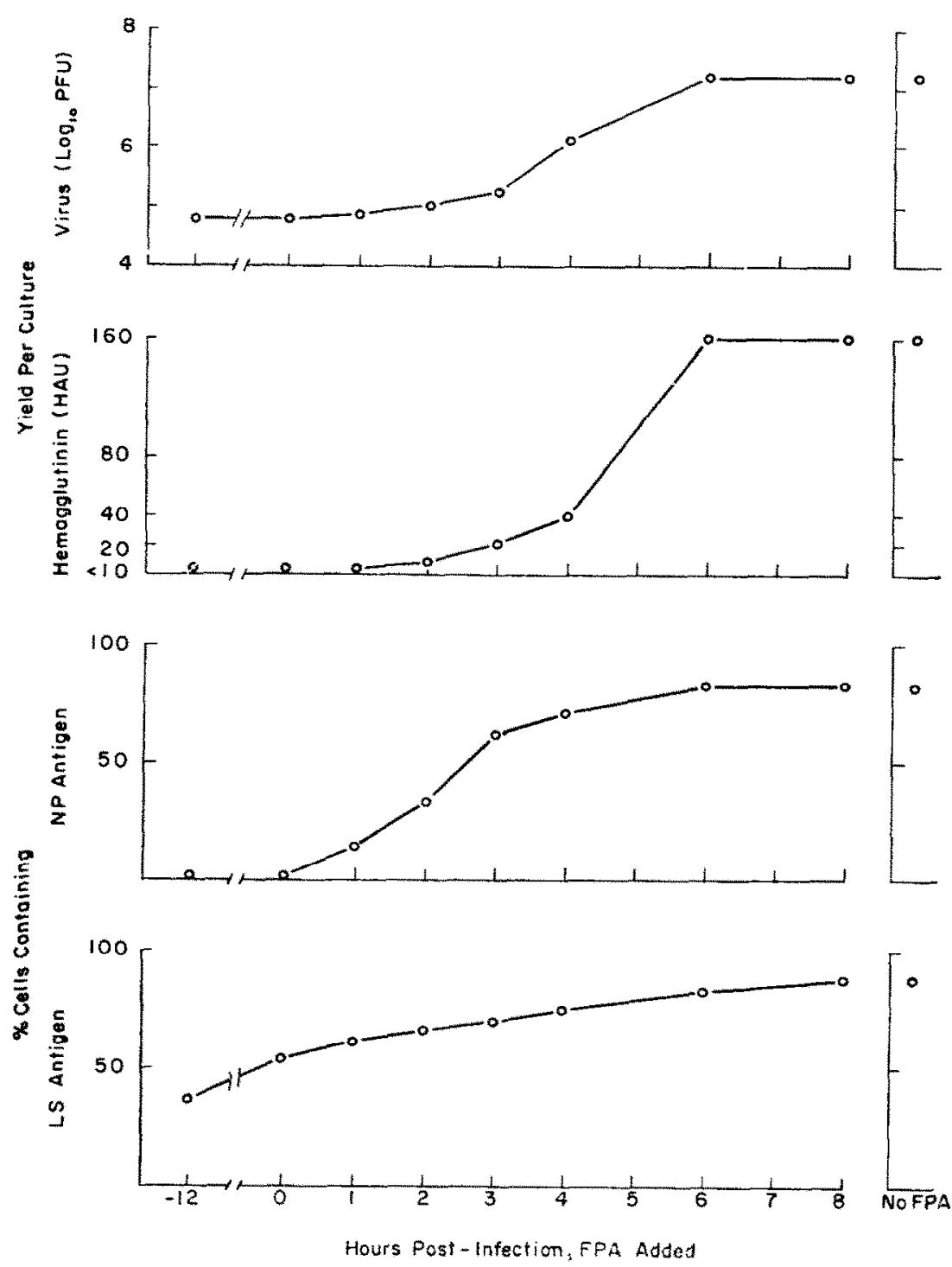

F1G. 6. The effect of $p$-fluorophenylalanine added at different times on the production of vaccinia virus, vaccinial hemagglutinin, NP antigen, and LS antigen in HeLa cells. Cultures were inoculated with virus at 0 time, incubated for 2 hours at $37^{\circ} \mathrm{C}$, washed with BSS, and incubated further. FPA (300 $\mu \mathrm{g} / \mathrm{ml}$ ) was added to cultures at the indicated times and was present in the RSS and fresh EM used for those eultures treated with FPA before and during the 2-hour adsorption period. The proportion of cells stained with fluorescent antibody was determined using coverslips fixed at 10 hours p.i. Replicate cultures were frozen at 24 hours p.i. for subsequent measurement of the yields of infectious virus and HA.

curred during the first few hours of infection and that these reactions werc completed by 6 hours p.i. However, since the time required for the added FPA to become effective was unknown and might have differed among the viral products examined, it was not considered valid to use these ex- periments for the exact timing of FPAsensitive reactions.

Although the observed inhibition by FPA of synthesis of NP and LS antigen in many of the infected cells may have accounted, at least in part, for the observed decreased production of infectious virus, it should be 


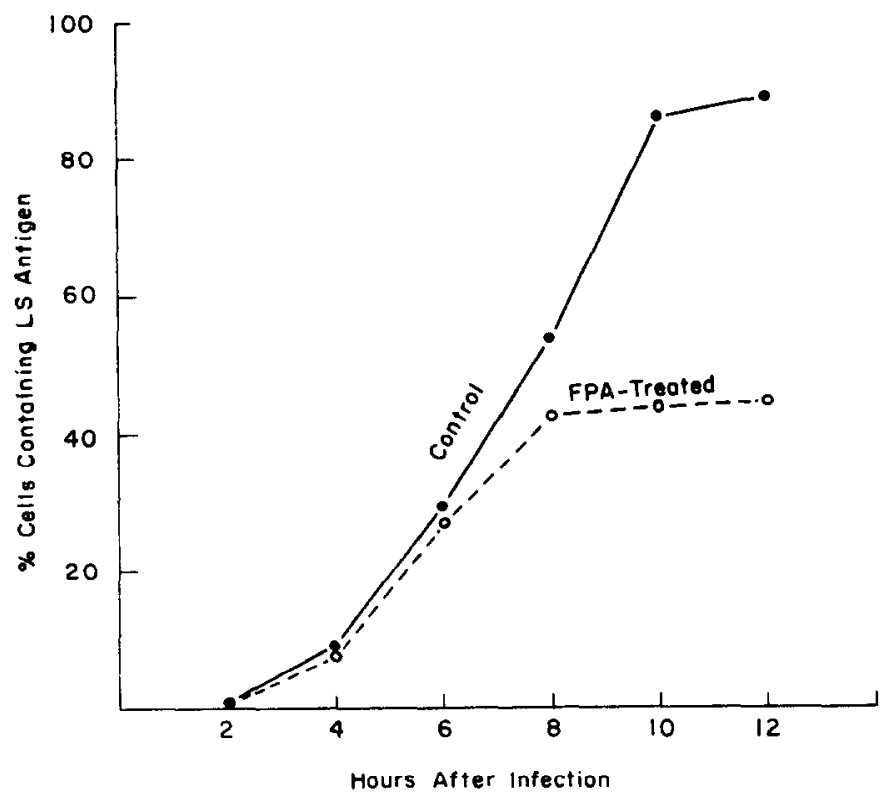

Fig. 7. The effect of $p$-fluorophenylalanine on the development of LS antigen in HeLa cells infected with vaccinia virus. Cell cultures were incubated with virus and FPA $(300 \mu \mathrm{g} / \mathrm{ml})$ for 2 hours at $37^{\circ} \mathrm{C}$, washed, and further incubated in EM containing the same concentration of FPA. Control cultures received virus and were treated in the same manner, without FPA. Coverslip preparations were fixed at the indicated times and stained with fluorescent antibody for determination of the proportion of cells containing LS antigen.

noted that when the analog was added to cultures at 3-4 hours p.i. large numbers of cells synthesized what appeared to be normal amounts of NP and LS antigen but the yields of virus and $\mathrm{HA}$ were definitely decreased. This suggested that in these cultures, neither the synthesis of NP or of LS antigen was the factor limiting yields of virus of $\mathrm{HA}$. However, that either the quantity or quality of these antigens, synthesized in the presence of FPA, was inadequate for optimal production of infectious virus could not be excluded.

Fewer cells produced LS antigen when FPA was added to cultures 12 hours before infection than when it was added at the time of infection. However, even after pretreatment of cultures with the analog, $37 \%$ of the cells were able to synthesize largc amounts of LS antigen. The continued synthesis by some FPA-treated infected cells of LS antigen was further examined by determining the proportion of cells containing the antigen at various times after infec- tion in the presence and the absence of the analog. As seen in Fig. 7, the curves for inhibited and control cultures are similar until about 8 hours p.i. After this time the number of cells containing LS antigen in FPA-inhibited cultures did not increase. It seemed that those cells destined to produce LS antigen early, initiated the process in the presence of FPA, and those which were to produce antigen late were prevented from doing so by the analog.

\section{Effect of FPA on DNA Synthesis}

Since H'PA-sensitive reactions seemed to precede the synthesis of viral antigens in the infected cells and since viral DNA synthesis occurs early in the replication of vaccinia virus (Salzman, 1960; Cairns, 1960; Magec et al., 1960; Easterbrook, 1961), it was of interest to determine the effect of FPA on the synthesis of viral DNA.

Because vaccinia virus DNA is synthesized de novo (Salzman, 1960; Sheek and Magee, 1961; Kit and Dubbs, 1962) and is 


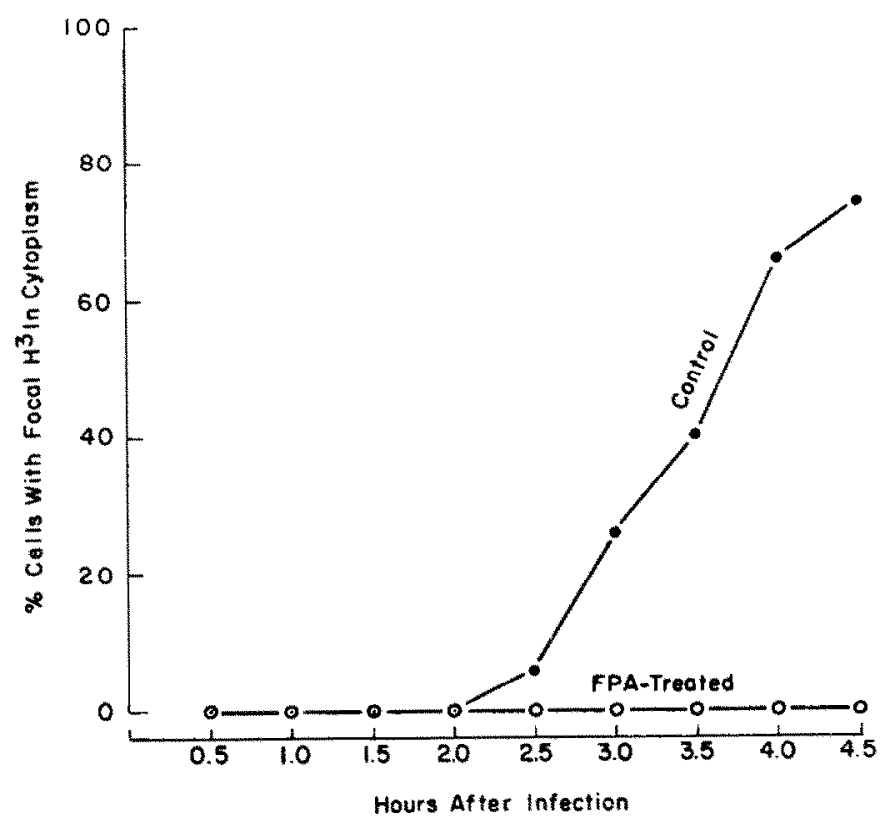

$\mathrm{FI} \alpha .8$. The effect of $p$-fluorophenylalanine on the incorporation of thymidine- $\mathrm{H}^{3}$ into viral DNA in HeLa cells infected with vaceinia virus. Coverslip cultures were incubated at $37^{\circ} \mathrm{C}$ with virus or with virus and FPA $(300 \mu \mathrm{g} / \mathrm{ml})$. At 0 time and at half-hour intervals after infection, thymidine- $\mathrm{H}^{3}(0.5 \mu \mathrm{c} / \mathrm{ml})$ was added to duplicate cultures. One-half hour after the thymidine $-\mathrm{H}^{\mathrm{s}}$ was added, pairs of cultures were fixed and processed for radioautography as described in Materials and Methods. The proportion of cells showing focal collections of silver grains over their cytoplasm was plotted against the time after infection when the cultures were fixed.

localized in the cytoplasm, it can be differentiated from cellular nuclear DNA by autoradiography (Cairns, 1960; Kato et al., 1960; Sheek and Magee, 1961). Accordingly, viral DNA synthesis in cells from infected and FPA-inhibited infected cultures was examined in terms of incorporation of thymidine- $\mathrm{H}^{3}$ into acid-insoluble cytoplasmic material. Thymidine- $\mathrm{H}^{3}$ was added to duplicate coverslip-cultures at 0 time and at half-hour intervals after infection. Cells from each pair were fixed and prepared for autoradiography one-half hour after they had received thymidine- $\mathrm{H}^{3}$.

In infected cultures exposed to thymidine$\mathrm{H}^{3}$ between 2.0 and 2.5 hours p.i., $5 \%$ of the cells showed focal collections of silver grains over their cytoplasm (Fig. 8). These cells were considered to have synthesized viral DNA during this interval. When exposed to thymidine- $\mathrm{H}^{3}$ between 4.0 and 4.5 hours p.i. $74 \%$ of the infected cells showed focal labeling of their cytoplasm. Cells from cultures that had received FPA with the virus showed no detectable incorporation of thymidine- $\mathrm{H}^{3}$ into acid-insoluble cytoplasmic material. However, if viral DNA synthesis had continued at a relatively slow rate in the presence of FPA, it might not have been detected by exposure of cells to thymidine- $\mathrm{H}^{3}$ for just 0.5 hour. Also, FPA might have delayed the onset of viral DNA synthesis until after 4.0 to 4.5 hours p.i., the last interval tested. Consequently, the experiment was repealed except that cultures were exposed to thymidine- $\mathrm{H}^{3}$ for longer intervals. Cultures that received FPA with the virus showed no focal cytoplasmic labeling even after incubation with thymidine- $\mathrm{H}^{3}$ from 0 to 5.0 hours p.i. or from 4.5 to 8.0 hours p.i. At the end of these respective intervals, 74 and $71 \%$ of cells from infected control cultures showed heavy focal cytoplasmic labeling. Similarly, staining cells with acridine orange at 5 and 8 hours p.i. revealed green fluorescent cytoplasmic inclusions, presumably viral DNA, in infected control cultures, but not in FPA- 
TABLE 1

EfFEct of $p$-Fturorophenylalanine on INCorporation of Thymidine-H ${ }^{3}$ INTO Nuclear DNA OF UNINFECTED AND VACCINIA VIRUSInfected Hela Cells as Determined by AUTORADIOGRAPHY ${ }^{a}$

\begin{tabular}{|c|c|c|c|c|}
\hline \multirow{3}{*}{$\begin{array}{l}\text { Interval of } \\
\text { exposure to } \\
\text { thymidine- } \mathrm{H}^{3} \\
\text { (hours p.i.) }\end{array}$} & \multicolumn{4}{|c|}{$\%$ Cells with nuclear labeling } \\
\hline & \multicolumn{2}{|c|}{ No FPA } & \multicolumn{2}{|c|}{ FPA added } \\
\hline & Control & Infected & Control & Infected \\
\hline $0-5.0$ & 52 & 26 & 54 & 47 \\
\hline $4.0-4.5$ & 36 & 14 & 41 & - \\
\hline $4.5-8.0$ & 63 & 34 & 58 & 61 \\
\hline
\end{tabular}

a Vaccinia virus (exposure multiplicity $=20$ ) was added to the indicated cultures. FPA to give a concentration of $300 \mathrm{~kg} / \mathrm{ml}$ was added at 0 time. All eultures were incubated for 2 hours at $37^{\circ} \mathrm{C}$, washed, and incubated further in EM at $37^{\circ} \mathrm{C}$. Those cultures with FPA or thymidine $\mathrm{H}^{3}$ during the 2-hour virus adsorption period received $\mathrm{EM}$ containing FPA or thymidine- $\mathrm{H}^{3}$ after the washes. At the indicated times cultures received thymidine- $\mathrm{H}^{3} \quad(0.5 \mu \mathrm{c} / \mathrm{ml})$ and at the end of the interval of exposure to thymidine- $\mathrm{H}^{3}$, cells on coverslips were fixed for determination of the proportion of cells containing $\mathrm{H}^{3}$ as described in Materials and Methods.

inhibited cultures. That FPA did not markedly interfere with the intracellular availability of thymidine- $\mathrm{I}^{3}$ was suggested by the observed incorporation of label into the nuclei of FPA-treated infected cells (see Table 1). Thus, $300 \mu \mathrm{g} / \mathrm{ml}$ of FPA added with the virus narkedly inhibited viral DNA synthesis whereas under similar conditions many infected cells had synthesized LS antigen.

In autoradiographic preparations from the above experiments it was found that in vaccinia-infected cultures the proportion of cells with label in their nuclei was approximately half that found in uninfected cultures (Table 1). FPA treatment of uninfected cultures did not significantly alter the proportion of cells incorporating thymidine- $\mathrm{H}^{3}$ into their nuclei. Cultures that received FPA with the virus showed essentially the same proportion of cells with nuclear label as the uninfected controls. Thus, vaccinia virus infection had decreased the number of cells ineorporating thymidine- $\mathrm{H}^{3}$ into nuclear
DNA, and this effect was not manifest when infected cultures were treated with FPA.

\section{DISCUSSION}

Differential inhibition by FPA of the synthesis of products of cells infected with RNA viruses has been previously reported (Zimmermann and Schäffer, 1960; Wecker and Schonne, 1961; Brown et al, 1961; Scholtissek and Rott, 1961; Levintow et al., 1962; Wecker et al., 1962). A similar phenomenon was observed in the present study of HeLa cells infected with vaceinia virus and treated with FPA. The amino acid analog, added at the time of infection, markedly inhibited the synthesis of viral DNA, NP antigen, infectious virus, and vaccinial HA but only partially inhibited the synthesis of LS antigen. By varying the dose of FPA or the time after infection at which the inhibitor was added to cultures, it was possible to reduce the yield of infectious virus to a greater extent than the yield of HA. In a similar manner, it was also possible to reduce markedly the yield of virus and allow the majority of the cells to produce what appeared to be large amounts of NP and LS antigen. PA reversed the FPAinduced inhibition of synthesis of these various products of the infected cells indicating the specific nature of the inhibition.

FPA may either block protein synthesis or substitute for PA in the protein synthesized (Cohen and Munier, 1959; Richmond, 1962). FPA inhibition of replication of vaccinia virus may be attributable to interference with the production of enzymes required for the synthesis of viral components or to the synthesis of aberrant viral proteins. Proteins containing FPA might be nonfunctional as constituents of infectious virus or nonfunctional as antigen in reacting with specific antibody. These two properties of a given protein would not necessarily be equally sensitive to modification by FPA. In the present study, a cell synthesizing FPA containing antigen might or might not have stained with fluoresceinlabeled antibody depending upon the degree of modification of the antigen.

The absence of detectable viral DNA synthesis in cultures treated with FPA at 
the time of infection implied the need for protein synthesis for viral DNA replication. This protein might be an uncoating enzyme as has been described for rabbitpox virus (Joklik, 1962) or an enzyme involved in the replication of viral DNA. Vaccinia virus infection has been found to induce marked increases in the activities of thymidine kinase (Green and Piña, 1962; McAuslan and Joklik, 1962; Kit et al., 1962; Magee, 1962) and DNA polymerase (Green and Piña, 1962; Magee, 1962).

Of particular interest was the finding that many cells in the FPA-inhibited infected cultures synthesized apparently large amounts of LS antigen under conditions which inhibited all detectable synthesis of viral DNA. This observation indicated that LS antigen synthesis had occurred in the absence of continued synthesis of viral DNA and possibly that a component of the original infecting virus was able to induce or direct the synthesis of IS antigen. It was in the hope of clarifying the relationship of viral DNA synthesis to viral antigen synthesis that a study was carried out on the effects of 5-fluoro-2'-deoxyuridine on the replication of vaccinia virus (Loh and Payne, 1965). It was found, as subsequently reported by others (Shatkin, 1963; Easterbrook, 1963), that cultures treated with the pyrimidine analog were able to synthesize some vaccinial protein.

If FPA inhibition of an uncoating enzyme was alone responsible for the apparent absence of viral DNA synthesis, it would follow that the production of LS antigen by cells not synthesizing viral DNA had been induced by infecting virus that had not been uncoated. However, it is possible that uncoating of virus did occur in those cells that synthesized LS antigen but not viral DNA. In this regard, it is of interest that Joklik (1962) found that about $16 \%$ of the rabbitpox virus normally uncoated was uncoated in cells treated with amounts of FPA comparable to those used in the present study.

With the immunofluorescence techniques available, only a relatively crude estimate of the quantity of NP or LS antigen per cell could be made. The minimum amount of antigen detected by immunofluorescent staining was unknown, and, although this was thought to be quite small, it was possible that a nonstained cell had synthesized some antigen. Further, the amount of antigen per cell in experimental cultures was judged by comparing the staining of these cells with that of control cells at various times after infection. Although two cells appeared to stain to the same degree, the possibility that they differed in their content of antigen could not be excluded.

Nevertheless, the observation that in an FPA-treated infected culture some cells produced no detectable LS or NP antigen while all others produced what appeared to be a normal amount of these antigens suggested that in some cells FPA interfered with a process required for the initiation of synthesis of the antigens and that in the remaining infected cells FPA did not interfere with either the initiation or continued production of these antigens. The synthesis of apparently normal amounts of IS and NP antigen by many cells under conditions which inhibited virus yield may have been attributable to the production of FPAcontaining antigens which were nonfunctional as constituents of infectious virus. It was equally possible, however, that the inhibition of virus yield under these conditions was related to FPA interference with the synthesis of proteins other than LS and NP antigen. Salzman et al. (1963) have reported that FPA interfered with the production of an essential viral protein, which in their experiments was formed only 30-45 minutes prior to the formation of infectious vaccinia virus. At present, the relationship of this "late" protein to LS and NP antigen is unknown.

In the present study, FPA added at 6 hours p.i. permitted synthesis of virus to continue for several hours and did not reduce the yield of infectious virus. However, Salzman et al. (1963) found that when FPA was added at 6 hours p.i. production of virus ceased in less than an hour and the yield of infectious virus was reduced by $90 \%$ or more. This difference in the results of the two investigations cannot be adequately explained. DL- $p$-Fluorophenylalanine was used in the present study, but Salzman et al. 
(1963) did not specify which isomeric form of the analog was used. The latter authors used concentrations of FPA and PA approximately one-tenth of those used here. Other factors that might have affected the reactions inhibited or the time required for added FPA to become effective and that differed in the two investigations include the strains of HeLa cells, the type of cell culture (suspension vs. monolayer), and the strain of virus.

The observed decrease in the proportion of nuclei incorporating thymidine- $\mathrm{H}^{3}$ after infection with vaccinia virus is in agreement with several previous reports (Hanafusa, 1960; Sheek and Magee, 1961; Kato et al., 1962; Kit and Dubbs, 1962) but differs from reports by Cairns (1960) and Shatkin and Salzman (1963). The latter authors found that the proportion of nuclei incorporating thymidine was not altered by infection with vaccinia virus. The difference between the observations of the two groups of investigators may be related to the finding of Shatkin and Salzman (1963) that limiting the supply of thymidylic acid decreased the rate of synthesis of cellular DNA, but not that of viral DNA. Other factors, such as the strain of virus or the type of cells used by the various investigators, also may have contributed to their differing results.

In the present study, although the decreased incorporation of thymidine- $\mathrm{H}^{3}$ into nuclei may reflect a decreased syuthesis of cellular DNA, virus-induced alterations in the size of the thymidylic acid pool might produce similar results (Newton et al., 1962). Whatever the explanation for the observed decreased proportion of muclei incorporating thymidine- $\mathrm{H}^{3}$ after infection with vaccinia virus, it is of interest that this decrease was not found when viral replication was inhibited by FPA. In noninfected cultures the analog had no effect on the number of nuclei incorporating thymidine- $\mathrm{H}^{3}$, a result indicating that nuclear DNA synthesis was direstly or indirectly affected by the virus and that this effect of the virus was inhibited by FPA.

\section{REFERENCES}

Ackermann, W. W., Rabson, A., and Kurtz, H. (1954). Growth characteristics of poliomyclitis virus in HeLa cell cultures: lack of parallelism in cellular injury and virus increase. $J$. Exptl. Med. 100, 437-450.

Armstrong, J. A., and Nrven, J. S. F. (1957). Fluorescence microseopy in the study of nucleic acids; histochemical observations on cellular and virus nucleic acids. Nature 180, 1335-1336.

Beveridge, W. I, B., and Burnet, F. M. (1946). The cultivation of viruses and rickettsiae in the chick embryo. Med. Res. Council Spec. Rept. Ser. 256.

Brown, F., Planteroge, D. N., and Stewart, D. L. (1961). Effect of $p$-fuorophenylalanine on the multiplication of foot-and-mouth disease virus. Nature 191, 414-415.

Burnet, F. M., And Stone, J. D. (1946). The hemagglutinins of vaccinia and ectromelia viruses. Australian J. Expll. Biol. Med. Sci. 24, 1-8.

CaIrns, J. (1960). The initiation of vaccinia infection. Virology 11, 603-623.

Cohen, G. N., and Munier, R. (1959). Effets des analogues structuraux d'amino acides sur la croissance, la synthèse de protéines et la synthèse d'enzymes chez Escherichia coli. Biochim. Biophys. Acta 31, 347-356.

CoHn, M. (1952). Techniques and analysis of the quantitative precipitin reaction: Reaction in liquid media. Methods Med. Res. 5, 301-335.

Coons, A. H., and Kaplan, M. H. (1950). Localization of antigen in tissue cells. II. Improvements in a method for the detection of antigen by means of fluorescent antibody. J. Exptl. Med. $91,1-13$.

Eatee, H., Oyama, V. I., Levy, M., and FreeMAN, A. E. (1957). Myoinositol as an essential growth factor for normal and malignant human cells in tissue culture. J . Biol. Chem. 226, 191-205.

Easterbrook, K. B. (1961). Analysis of the early stages of vaceinia virus infection in $\mathrm{KB}$ cells using sodium azide. Virology $15,417-427$.

Easterbrook, K. B. (1963), Conservation of vaccinial DNA during an abortive cycle of multiplication. Virology 21, 508-510.

Grene, M., and PIÑA, M. (1962). Stimulation of DNA-synthesizing enzymes of cultured human cells by vaccinia virus infection. Virology 17, 603604 .

Hanafusa, T. (1960). Alteration of nucleic acid metabolism of host cells by active and inaotivated forms of vaccinia virus. Biken's J $3,313-$ 327.

JoKLIK, W. K. (1062). The multiplication of poxvirus DNA. Cold Spring Harbor Symp. Quant. Biol. 27, 199-208.

KATO, S., KAmeYama, S, and KAMAIronA, J. (1960). Autoradiography of cells infected with variola and cowpox viruses with $\mathrm{H}^{3}$-thymidine. Biken's J. 3, 183189. 
Kato, S., KuRisu, M., and Kamahora, J. (1962). Effects of cytoplasmic DNA synthesis upon nuclear DNA synthesis in poxvirus-infected cells. Biken's $J$. 5, 227-231.

Kempe, C. H. (1956). Variola and vaccinia. In "Diagnostic Procedures for Virus and Rickettsial Diseases" (T. Francis, Jr., ed.), 2nd ed. Am. Public Health Assoc., New York.

KIt, S., and DubBs, D. R. (1962). Biochemistry of vaecinia-infected mouse fibroblasts (strain I-M). II. Properties of the chromosomal DNA of infected cells. Virology 18, 286-293.

Kit, S., Dubbs, D. R., and Pimkarski, L. J. (1962). Enhanced thymidine phosphorylating activity of mouse fibroblasts (strain L-M) following vaccinia infection. Biochem. Biophys. Res. Commun. 8, 72-75.

Kit, S., Prekarski, L. J., and Dubas, D. R. (1963). Induction of thymidine kinase by vaccinia-infected mouse fibroblasts. J. Mol. Biol. 6, 22-33.

Levintow, L., Thorén, M. M., Darneli, J. E., JR., and Hooper, J. L. (1962). Effect of $p$-fluorophenylalanine and puromycin on the replication of poliovirus. Virology 16, 220-229.

LOH, P. C., and PAYNe, F. E. (1965). Effect of 5fluoro- $2^{\prime}$-deoxyuridine on the synthesis of vaccinia virus. Virology 25, 575-584.

LoH, P. C., and RigGs, J. L. (1961). Demonstration of the sequential development of vaccinial antigens and virus in infected cells: Observations with cytochemical and differential fuorescent procedures. J. Exptl. Med. 114, 149-160.

McAuslan, B. R., and Joklik, W. K. (1962). Stimulation of the thymidine phosphorylating system in HeLa cells on infection with poxvirus. Biochem. Biophys. Res. Commun. 8, $486-491$.

MAGEE, W. E. (1962). DNA polymerase and deoxyribonueleotide kinase activities in cells infected with vaccinia virus. Virology 17, 604-607.

Magee, W. E., Sheek, M. R., and Burrous, M. J. (1960). The synthesis of vaccinial deoxyribonucleic acid. Virology 11, 296-299.

Messier, B., and Leblond, C. P. (1957). Preparation of coated radioautographs by dipping sections in fluid emulsion. Proc. Soc. Exptl. Biol. Med. 96, 7-10.
Newtox, A., Dendy, P. P., Smith, C. L., and WILDY, P. (1962). A pool size problem associated with the use of tritiated thymidine. Nature 194, 886887 .

Richmond, M. H. (1962). The effect of amino acid analogues on growth and protein synthesis in microorganisms. Bacteriol. Rev. 26, 398-420.

SAlzMAN, N. P. (1960). The rate of formation of vaceinia deoxyribonucleie acid and vaccinia virus. Virology 10, 150-152.

Salzman, N. P., Shatkin, A. J., and Sebring, E. D. (1963). Viral protein and DNA synthesis in vaccinia virus-infected HeLa cell oultures. Virology 19, 542-550.

Scholtissek, C., and Rott, R. (1961). Influence of $p$-fluorophenylalanine on the production of viral ribonucleic acid and on the utilizability of viral protein during multiplication of fowl plague virus. Nature 191, 1023-1024.

Shatkrn, A. J. (1963). The formation of vaccinia virus protein in the presence of 5 -fluorodeoxyuridine. Virology 20, 292-301.

Shatkin, A. J., and Salzman, N. P. (1963). Deoxyribonucleic acid synthesis in vaceinia virus-infected HeLa cells. Virology 19, 551-560.

Shedlovskx, T., and Smadel, J. E. (1942). The LS antigen of vaccinia. II. Isolation of a single substance containing both $\mathrm{L}$ and $\mathrm{S}$ activity. J. Exptl. Med. 75, 165-178.

Sheek, M. R., and MAGEe, W. E. (1961). An autoradiographic study on the intracellular development of vaceinia virus. Virology 15, 146163.

Smadel, J. E., Rivers, T. M., and Hoagland, C. L. (1942). Nucleoprotein antigen of vaccine virus. I. A new antigen obtained from elementary bodies of vaceinia. Arch. Pathol. 34, 275285.

Wecker, E., and Schonne, E. (1961). Inhibition of viral RNA synthesis by parafluorophenylalanine. Proc. Natl, Acad. Sci. U. S. 47, 278-282. Wecker, E., Hummeler, K., and Goetz, $O$. (1962). Relationship between viral RNA and viral protein synthesis. Virology 17, 110-117.

ZIMMermanN, T., and SCHÄFER, W. (1960). Effect of $p$-fiuorophenylalanine on fowl plague virus multiplication. Virology 11, 676-698. 